Check for updates

Cite this: RSC Adv., 2018, 8, 14025

\title{
Enhanced performance of tin halide perovskite solar cell by addition of lead thiocyanate $\uparrow$
}

\author{
Fengqiang Gao, Chunhai Li, Liang Qin, Lijie Zhu, Xin Huang, Huan Liu, Liming Liang, \\ Yanbing Hou, (D) $\dagger^{*}$ Zhidong Lou, (D) Yufeng Hu (D) and Feng Teng:*
}

\begin{abstract}
Organic-inorganic hybrid halide perovskites have attracted great attention as a new type of photovoltaic materials. However, lead (Pb) perovskite solar cells (PSCs) would cause environmental pollution in future large-scale applications. Therefore, it is imperative to find environmentally-friendly metals to replace lead. Although tin (Sn) halide perovskites can be regarded as a valid alternative to lead perovskites, their poor stability and lower conversion efficiency hinder the substitution of $\mathrm{Sn}$ for $\mathrm{Pb}$. In this work, highly uniform and pinhole-free perovskite films were prepared by the introduction of a small amount of lead thiocyanate in precursor solutions. The $\mathrm{CH}_{3} \mathrm{NH}_{3} \mathrm{Snl}_{3}\left(\mathrm{MASnl}_{3}\right)$ films with $\mathrm{Pb}$ additive show an absorption edge of $950 \mathrm{~nm}$. Besides, lead ions can depress the LUMO energy level of Sn-based perovskite materials, which is a benefit to an increase in the opencircuit voltages of PSCs. Consequently, the enhanced performance was achieved in the PSCs based on $\mathrm{MASnl}_{3}$ with a fill factor of $66 \%$, open circuit voltage of $0.54 \mathrm{~V}$ and maximum power conversion efficiency of $6.03 \%$.
\end{abstract}

Received 26th January 2018 Accepted 2nd April 2018

DOI: $10.1039 / \mathrm{c} 8 \mathrm{ra00809d}$

rsc.li/rsc-advances

instability of $\mathrm{MASnI}_{3} \mathrm{PSCs}^{19}$ So the repeatability of $\mathrm{MASnI}_{3}$ PSCs is limited extremely; (2) the reaction between $\mathrm{SnI}_{2}$ and organic ammonium salts is faster than that between $\mathrm{PbI}_{2}$ and organic ammonium salts, which results in the uncontrollability of film morphology under solution processing. ${ }^{20}$ Since 2014, some breakthroughs have been made in these aspects. For example, the doped hole density in Sn-based perovskites reduced remarkably by adding a small amount of $\mathrm{SnF}_{2} \cdot{ }^{19}$ Dimethyl sulfoxide (DMSO) as the precursor solvent formed a $\mathrm{SnI}_{2} \cdot 3$ DMSO intermediate phase with $\mathrm{SnI}_{2}$, which retarded the rapid crystallization of Sn-based perovskites and benefitted the formation of uniform films, firstly reporting the $\mathrm{MASnI}_{3}-$ based PSCs with a PCE of $5.23 \%{ }^{20}$ Subsequently, it was demonstrated that a PCE of $6.4 \%,{ }^{15}$ with a high open circuit voltage $\left(V_{\mathrm{oc}}\right)$ of $0.88 \mathrm{~V}$ and a fill factor $(\mathrm{FF})$ of $59 \%$, for Sn-based perovskites solar cells was achieved, which are so far the best PCE and FF for MASnI ${ }_{3}$-based PSCs. ${ }^{21}$ F. Zuo et al. reported a binary-metal planar MASnI $_{3}$-based solar cell that poly(3,4ethylenedioxythiophene) polystyrene sulfonate (PEDOT : PSS) and [6,6]-phenyl-C61-butyric acid methyl ester (PCBM) were considered as HTM and ETM, respectively. But they only achieved a PCE of $0.04 \%$ and a FF of $25 \%{ }^{21} \mathrm{~W}$. Liao et al. reported a Sn-based PSCs with $40 \%$ lead iodide and they achieve a PCE of $15.08 \%$, which is the maximun efficency for the solar cells based on $\mathrm{Sn} / \mathrm{Pb}$ halide-based perovskite. ${ }^{22}$

In this work, the lead thiocyanate is first used as lead source for $\mathrm{Sn} / \mathrm{Pb}$ halide-based perovskite solar cells. The introduction of a small amount of lead thiocyanate can improved film morphology significantly. No significant $\mathrm{SCN}-$ ion incorporation into the resulting final perovskite films was found. We fabricated the

Key Laboratory of Luminescence and Optical Information, Ministry of Education, Beijing Jiao Tong University, Beijing, 100044, China. E-mail: ybhou@bjtu.edu.cn $\dagger$ Electronic supplementary information (ESI) available. See DOI: 10.1039/c8ra00809d

\$ These authors contributed equally to this work. 
devices with a structure of indium tin oxide (ITO)/poly(3,4ethylenedioxythiophene)polystyrene sulfonate (PEDOT : PSS)/ perovskite/PCBM/Polyetherimide(PEI)/aluminium(Al) to study the performance of these perovskites in solar cells. An optimal PCE of $6.03 \%$ for the devices based on $\mathrm{MASnI}_{3}$ has been achieved by the addition of $20 \mathrm{~mol} \% \mathrm{~Pb}(\mathrm{SCN})_{2}$, along with a $V_{\mathrm{oc}}$ of $0.54 \mathrm{~V}$ and a $\mathrm{FF}$ of $66 \%$.

\section{Results and discussion}

The $\mathrm{MASnI}_{3}$ films were deposited on the PEDOT : PSS-coated ITO substrates via a one-step procedure with $0,5 \%, 10 \%$, $15 \%, 20 \%, 25 \%$, and $30 \%$ mole lead thiocyanate in the precursor solutions. Perovskite active layers were fabricated by an ant solvent-assisted crystallization approach. Comparing several different antisolvents, we found that the mixed solvent of toluene: chloroform ( $7: 3$ in volume) not only assisted the crystallization of the perovskite films but also improved their morphologies. The full-coverage and pinhole-free $\mathrm{MASnI}_{3}$ films were prepared by the mixed antisolvent, but it led to a problem that the surface roughness reached a few tens of nanometres as shown in Fig. S1. $\dagger$ This might be attributed to the phase separation due to the different solvent volatilization rates. The scanning electron microscopy (SEM) image in Fig. S2† shows the detailed morphology. To overcome this situation, vacuum treatment was used before annealing to remove the solvents rapidly, which suppressed the phase separation to some degree. This is named the vacuum-assisted annealing (VAA). The schematic of the preparation procedure of the perovskite films is shown in Fig. 1.

The top-view SEM images, shown in Fig. 2, reveal a typical pinhole phenomenon of Sn-based perovskite films formed by a solution process. One can find that the nanometre-size pinholes fill around grain boundaries, as shown in Fig. 2a. The presence of pinhole is related to an uncontrollable crystallization which is attributed to the faster reaction between the $\mathrm{SnI}_{2}$ film and the methylammonium iodide. ${ }^{20}$ Fig. $\mathrm{S} 3 \uparrow$ exhibits that the pinhole size becomes larger and the density of the pinholes declines with the increasing amount of $\mathrm{Pb}(\mathrm{SCN})_{2}$. When the amount of $\mathrm{Pb}(\mathrm{SCN})_{2}$ is up to $20 \%$, the pinholes disappear, as shown in Fig. 2b. Takamichi Yokoyama et al. proved that the Gibbs free energy to form MASnI $_{3}$ perovskite is lower than that of $\mathrm{Pb}$-base perovskite. ${ }^{23}$ Therefore addition of lead can slow the reaction rate between $\mathrm{SnI}_{2}$ and methylammonium iodide, which lead that the pinhole phenomenon is

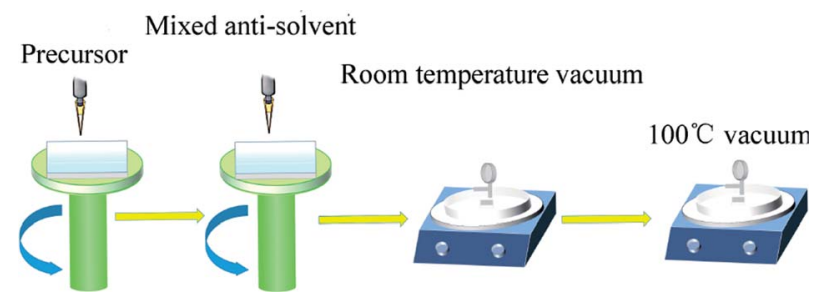

Fig. 1 Schematic of the preparation procedure of Sn-based perovskites.
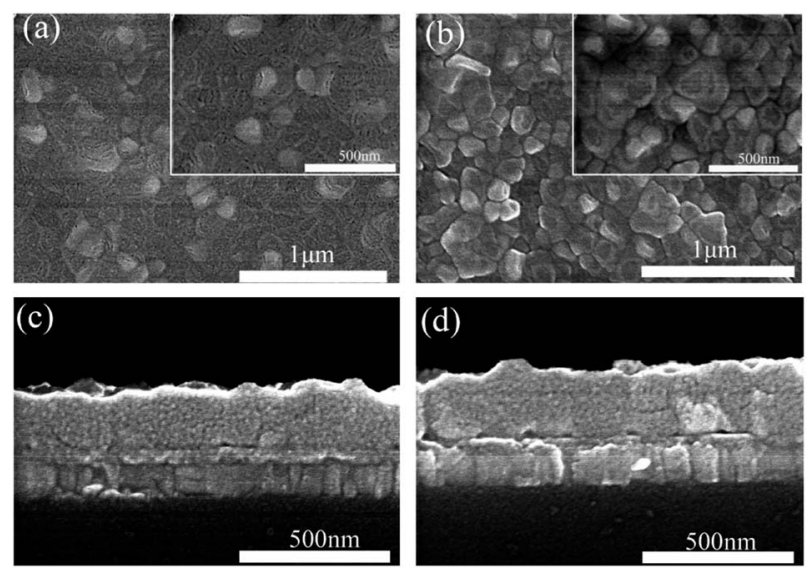

Fig. 2 Top-view SEM ( $a$ and b) and cross sectional SEM (c and $d$ ) images of the MASnl 3 films without (a and c) and with $20 \% \mathrm{~Pb}(\mathrm{SCN})_{2}(\mathrm{~b}$ and $d$ ) in the precursors.

improved. The cross-sectional SEM images in Fig. 2c and d, indicate that $\mathrm{Pb}(\mathrm{SCN})_{2}$ exhibits no significant influence on the film thickness and it holds the scope of 250-260 $\mathrm{nm}$.

There is an apparent characteristic peak of $\mathrm{PbI}_{2}$ at $12.8^{\circ}$ in the X-ray diffraction (XRD) patterns of the Sn-based perovskite films various amounts of $\mathrm{Pb}(\mathrm{SCN})_{2}$ additives in the precursors shown in Fig. $\mathrm{S} 4, \dagger$ which reveals the presence of $\mathrm{PbI}_{2}$ in the films processed with $\mathrm{Pb}(\mathrm{SCN})_{2}$. However, there are no diffraction peaks for the leftover excess $\mathrm{Pb}(\mathrm{SCN})_{2}$ phase, as shown in Fig. 3a. In addition, the peak positions at the (110) planes of the $\mathrm{MASnI}_{3}$ films move slightly to the smaller diffraction angle, as shown in Fig. S5. $\dagger$ We believe that part of lead ions of a larger radius incorporated into the lattice and led to the lattice expansion. Since the XRD peaks of $\mathrm{Pb}(\mathrm{SCN})_{2}$ are absent, it is considered that most SCN ions do not remain in the final
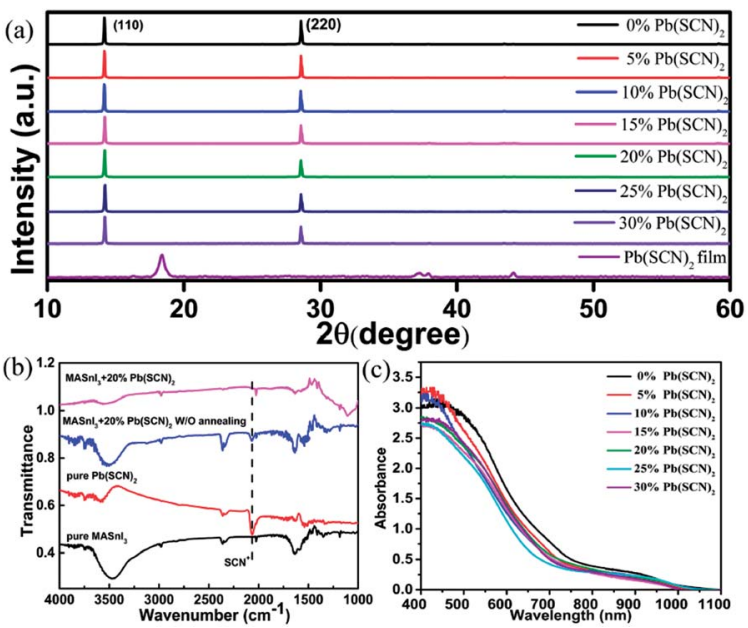

Fig. 3 (a) XRD patterns of a $\mathrm{Pb}(\mathrm{SCN})_{2}$ film and the $\mathrm{MASnl}_{3}$ films with various concentrations of $\mathrm{Pb}(\mathrm{SCN})_{2}$ additive in the precursors. (b) FTIR spectra of the films of $\mathrm{Pb}(\mathrm{SCN})_{2}, \mathrm{MASnl}_{3}$ and $\mathrm{MASnl}_{3}$ with $20 \%$ $\mathrm{Pb}(\mathrm{SCN})_{2}$ additive with and without annealing. (c) Absorbance spectra of the $\mathrm{MASnl}_{3}$ films with various concentrations of $\mathrm{Pb}(\mathrm{SCN})_{2}$ additives in the precursors. 
perovskite thin films. Our speculation is further confirmed by Fourier Transform Infrared (FTIR) measurements. The FTIR spectra of the thin films of pure $\mathrm{Pb}(\mathrm{SCN})_{2}$, pure $\mathrm{MASnI}_{3}, \mathrm{MASnI}_{3}$ with $20 \% \mathrm{~Pb}(\mathrm{SCN})_{2}$ additive in the precursor are shown in Fig. 3b. The FTIR peak at the wavenumber of $2065 \mathrm{~cm}^{-1}$, which is related to SCN ions, is clearly seen in the spectrum of the perovskite film with $20 \% \mathrm{~Pb}(\mathrm{SCN})_{2}$ additive in the precursor before it was annealed. However, this peak is absent after annealing, which suggests that SCN ions disappear in the perovskite films during the annealing. Further characterization was conducted by SEM-based X-ray energy dispersive spectroscopy (EDS). As shown in Fig. S6, $\uparrow$ the EDS spectrum taken from the interior of a grain shows a Sn to I atomic ratio of $1: 3.22$, close to that in $\mathrm{MASnI}_{3}$, and only a trace amount of $\mathrm{Pb}$ but no $\mathrm{S}$ can be detected. Fig. $\mathrm{S} 7 \dagger$ illustrates that the intensity of the characteristic peaks of $\mathrm{PbI}_{2}$ at $12.8^{\circ}$ is obviously enhanced after annealing. This is probably caused by the volatilization of SCN and the formation of $\mathrm{PbI}_{2}$, therefore, almost no SCN ions remain in the final perovskite thin film, unlike the results reported in recent literatures. ${ }^{24}$ To explore the distribution of $\mathrm{Pb}$, the SEM-EDS elemental mappings of $\mathrm{Pb}, \mathrm{Sn}$ and $\mathrm{I}$ for the $\mathrm{MASnI}_{3}$ film have been tested, as shown in Fig. 4 . It is clearly observed that the element of $\mathrm{Pb}$ evenly distributes in the crystal grain. $\mathrm{CH}_{3} \mathrm{NH}_{3}[\mathrm{SCN}]$ has a larger enthalpy of formation than $\mathrm{CH}_{3} \mathrm{NH}_{3} \mathrm{I}$, which means that the $\mathrm{SCN}^{-}$anion is more apt to form ionic bonding with the $\mathrm{CH}_{3} \mathrm{NH}_{3}{ }^{+}$cation than the $\mathrm{I}^{-}$anion. ${ }^{25}$ The mechanism of the $\mathrm{Pb}(\mathrm{SCN})_{2}$ inducing recrystallization can be speculated by the following chemical equation:

$$
\begin{aligned}
& 2(x+y) \mathrm{CH}_{3} \mathrm{NH}_{3} \mathrm{I}+y \mathrm{SnI}_{2}+x \mathrm{~Pb}(\mathrm{SCN})_{2} \rightarrow \\
& y \mathrm{CH}_{3} \mathrm{NH}_{3}(\mathrm{Sn}+\mathrm{Pb}) \mathrm{I}_{3}+2 \mathrm{XCH}_{3} \mathrm{NH}_{3} \cdot \mathrm{SCN}+(x-y) \mathrm{PbI}_{2}
\end{aligned}
$$

The excess $\mathrm{PbI}_{2}$ can reduce the absorbance of the perovskite films as shown in Fig. 3c, which would result in a decrease in $J_{\text {sc }}$. In order to further understand the effects of $\mathrm{Pb}(\mathrm{SCN})_{2}$ on the $\mathrm{MASnI}_{3}$ thin films, the photoluminescence (PL) spectra of the films developed from the precursor solutions with different
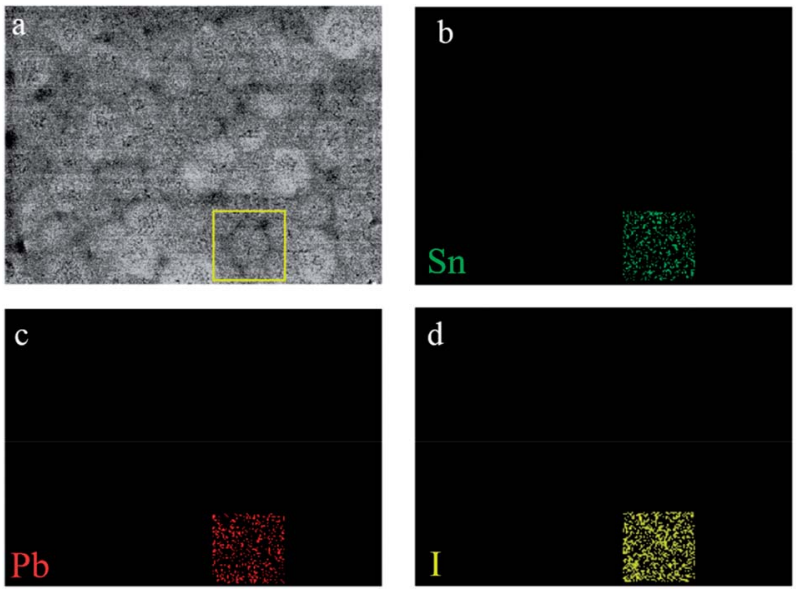

Fig. 4 Top-view SEM images of the $\mathrm{MASnl}_{3}$ films with $20 \% \mathrm{~Pb}(\mathrm{SCN})_{2}$ additive (a). SEM-EDS elemental mappings of Sn (green) (b), Pb (red) (c), and I (yellow) (d) for the MASnl 3 film.
$\mathrm{Pb}(\mathrm{SCN})_{2}$ concentrations have been measured, as shown in Fig. S8. $\dagger$ The PL intensity is enhanced with the increasing amount of $\mathrm{Pb}(\mathrm{SCN})_{2}$, thus, we speculate that the grain boundaries (GBs) in the perovskite films may be passivated by the excess $\mathrm{PbI}_{2}$ at the GBs and which can exhibit beneficial effects on the cell performance, as reported by others. ${ }^{26}$

We fabricated planar heterojunction photovoltaic devices employing the Sn-based perovskites as active layers. Fig. 5a indicates the inverted device structure adopted in this work.

The effects of the concentration of $\mathrm{Pb}(\mathrm{SCN})_{2}$ additive on the device performance of the Sn-based PSCs have been investigated. Fig. $5 \mathrm{~b}$ shows the $J-V$ curves for the PSCs prepared with different concentrations of $\mathrm{Pb}(\mathrm{SCN})_{2}$ under forward voltage scanning. The best performance has been acquired in the devices with $\mathrm{MASnI}_{3}$ prepared from the precursor solution with $20 \% \mathrm{~Pb}(\mathrm{SCN})_{2}$. The $J_{\mathrm{sc}}$ begins to decline when the amount of $\mathrm{Pb}(\mathrm{SCN})_{2}$ is more than $20 \%$. The reduction of $J_{\mathrm{sc}}$ is related with the decline of the absorbance of the perovskite films, and that enables the cells with a low $J_{\mathrm{sc}}$. Besides, the $\mathrm{Pb}$ ions can lower the LUMO level of Sn-I perovskite materials and increase the open circuit voltage of solar cells. ${ }^{27-33}$ As shown in Table S1 (ESI $\dagger$ ), the FF of the device also gains an obvious improvement with the addition of $\mathrm{Pb}(\mathrm{SCN})_{2}$. The high $\mathrm{FF}$ value can be ascribed to suppressed defect-mediated carrier recombination, as well as balanced carrier transport. $^{34,35}$ The cell with the perovskite absorber from the precursor solution without $\mathrm{Pb}(\mathrm{SCN})_{2}$ only achieves a PCE of $0.87 \%$ with a $J_{\mathrm{sc}}$ of $5.37 \mathrm{~mA} \mathrm{~cm}{ }^{-2}$, an $V_{\text {oc }}$ of $0.30 \mathrm{~V}$, and a FF of $54 \%$. The cell using the perovskite absorber with $20 \% \mathrm{~Pb}(\mathrm{SCN})_{2}$ in the precursor realizes a PCE $5.69 \%$ with a $J_{\mathrm{sc}}$ of $17.69 \mathrm{~mA} \mathrm{~cm}^{-2}$, an $V_{\mathrm{oc}}$ of $0.50 \mathrm{~V}$, and a $\mathrm{FF}$ of $64 \%$, revealing significantly improved FF and PCE. Fig. S9 $\dagger$ shows the $J-V$ curves under reverse voltage scanning, and we can find that the $V_{\text {oc }}$ is still on the rise while the $J_{\mathrm{sc}}$ reaches its maximum value as the amount of $\mathrm{Pb}(\mathrm{SCN})_{2}$ reaches $20 \%$. This is basically consistent with the law of $J-V$ curves under forward voltage scanning. The $J-V$ curves of the PSCs with $20 \%$ $\mathrm{Pb}(\mathrm{SCN})_{2}$ added in the perovskite precursor with the vacuum-
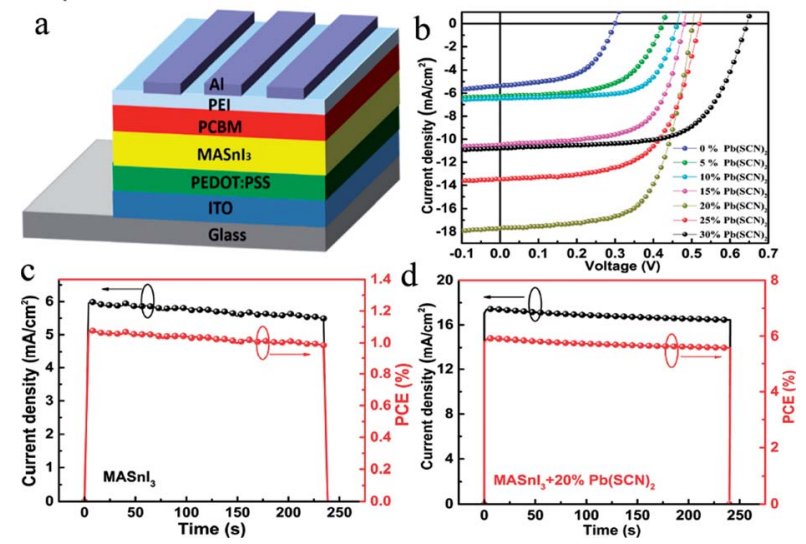

Fig. 5 (a) Schematic of the device structure of the solar cells. (b) J-V curves of the cells prepared using MASnl 3 with various concentrations of $\mathrm{Pb}(\mathrm{SCN})_{2}$ additives in the precursors, measured under forward voltage scanning. Steady-state efficiencies and current densities of the devices using $\mathrm{MASnl}_{3}$ without (c) and with $20 \% \mathrm{~Pb}(\mathrm{SCN})_{2}$ (d) at constant bias voltages of $0.18 \mathrm{~V}$ and $0.41 \mathrm{~V}$, respectively. 
assisted annealing (VAA) and without vacuum treatment were also tested. The film without vacuum treatment has an increased surface roughness, and makes the coverage is not complete, so these lead to the increase of the leakage current and the decrease of the fill factor, as shown in Fig. S10. $\dagger$ Therefore, the results prove that the vacuum-assisted annealing (VAA) is indeed an effective method to improve the device performance.

Fig. 5c and d show the steady-state efficiencies and current densities of the solar cells without and with $20 \% \mathrm{~Pb}(\mathrm{SCN})_{2}$ additive in the precursors under the standard illumination of AM 1.5 G. From the figures, one can find that the addition of $\mathrm{Pb}(\mathrm{SCN})_{2}$ cannot improve the stability, but enhances significantly the efficiency of the Sn-perovskite solar cells. The performance of the devices in the air without encapsulation have been tracked. As shown in Fig. S11, $\uparrow$ the PCE of the $\mathrm{MASnI}_{3}$ PSCs decays to $11 \%$ of its original value within $10 \mathrm{~min}$, while the PCE of the perovskites PSC fabricated by the solution with $20 \%$ $\mathrm{Pb}(\mathrm{SCN})_{2}$ retains $50 \%$ of its original value for over $100 \mathrm{~min}$. The reason for the fast degradation of the $\mathrm{MASnI}_{3}$ PSCs could be attributed to the fast oxidation of $\mathrm{MASnI}_{3}$ under the presence of oxygen and moisture in the air. However, the compact morphology of $20 \% \mathrm{~Pb}(\mathrm{SCN})_{2}$ perovskites PSCs slows down this oxidation process, which results in a more stable device performance.

Fig. 6a shows the external quantum efficiency (EQE) spectra of the cells using perovskite absorbers prepared with $0,10 \%$, $20 \%, 30 \% \mathrm{~Pb}(\mathrm{SCN})_{2}$ additive in the precursors. The devices with a higher amount of $\mathrm{Pb}(\mathrm{SCN})_{2}$ exhibit larger EQE. The reduction of the defects makes it more capable of collecting charge but it will severely affect the absorption when the lead content is further increased to $30 \%$. The $J-V$ curves of the maximum PCE cell with $20 \% \mathrm{~Pb}(\mathrm{SCN})_{2}$ are shown in Fig. S13. $\dagger$ The photovoltaic parameters were measured under both reverse and forward
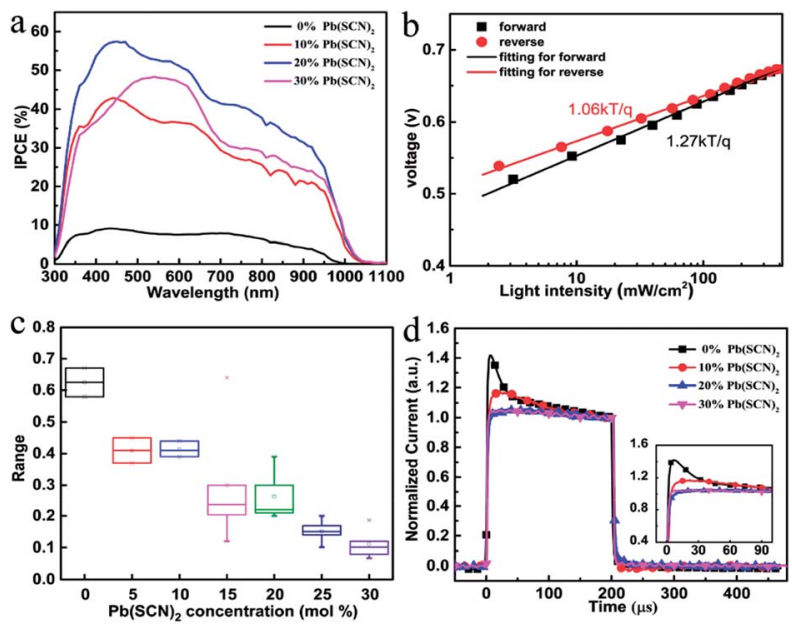

Fig. 6 (a) External quantum efficiency (EQE) spectra of the solar cells based on $\mathrm{MASnl}_{3}$ with various concentrations of $\mathrm{Pb}(\mathrm{SCN})_{2}$ additives in the precursors. (b) Open circuit voltage $\left(V_{O C}\right)$ of the perovskite PSCs with $20 \% \mathrm{~Pb}(\mathrm{SCN})_{2}$ additive plotted against incident light intensity. (c) The differences values of the ideality factor $n$ of the Sn perovskitebased PSCs with different $\mathrm{Pb}(\mathrm{SCN})_{2}$ concentration. (d) Transient photocurrent (TPC) response of the solar cells using $\mathrm{MASnl}_{3}$ with different $\mathrm{Pb}(\mathrm{SCN})_{2}$ concentrations. voltage scanning, as shown in Table S2. Fig. S14† shows the EQE spectra of the maximum PCE cells using the perovskite absorbers with $20 \% \mathrm{~Pb}(\mathrm{SCN})_{2}$ additive in the precursor. The integrated current densities based on these curves are $16.15 \mathrm{~mA}$ $\mathrm{cm}^{-2}$ for the cells using perovskite absorbers with $20 \%$ $\mathrm{Pb}(\mathrm{SCN})_{2}$ in the precursors.

To further clarify the charge recombination processes in the Sn-based PSCs, the light-intensity-dependent characterization was investigated. The light-intensity-dependent $V_{\text {OC }}$ provides critical insights into the mechanism of the recombination processes in the PSC devices. The relationship between $V_{\mathrm{OC}}$ and light intensity can be expressed as:

$$
V_{\mathrm{oc}}=\frac{n k T}{q} \ln \left(\frac{J_{\mathrm{ph}}}{J_{\mathrm{o}}}+1\right)
$$

where $q$ is the elementary charge, $k$ is the Boltzmann constant, $T$ is the absolute temperature, $J_{\mathrm{ph}}$ is the density of photogenerated current and $J_{\mathrm{o}}$ is the saturation one, and $n$ is an ideality factor..$^{36-39}$ The value of $n$ can reflect the recombination process. For bimolecular charge carrier recombination, the ideality factor $n$ approaches 1 . Whereas, when $n$ approaches 2 , trap-assisted Shockley-Read-Hall (SRH) type recombination is dominant. ${ }^{39-41} V_{\mathrm{OC}}$ as a function of the incident light intensity $(I)$ is plotted on a linear-log scale as shown in Fig. 6b for the PSCs with $20 \% \mathrm{~Pb}(\mathrm{SCN})_{2}$. Here two scan directions of the light intensity were employed to study the charge recombination process. The ideality factors for the forward and reverse light intensity scans are 1.27 and 1.06, respectively, which reveal that the bimolecular charge carrier recombination is dominant in the Sn-based PSCs with $20 \% \mathrm{~Pb}(\mathrm{SCN})_{2}$. The difference in the values of $n$ is attributed with the deep-level defects that cause the delay in the detrapping of trapped carriers. For the sake of quantitative analysis, the ideality factor difference, defining as the difference between the forward and reverse light intensity scans can reflect the amount of deep defects. The differences of the ideality factor of the Sn-based PSCs with different $\mathrm{Pb}(\mathrm{SCN})_{2}$ concentrations were evaluated. As shown in Fig. 6c, the ideality factor difference decrease with increasing the amounts of $\mathrm{Pb}(\mathrm{SCN})_{2}$, which means that the introduction of $\mathrm{Pb}(\mathrm{SCN})_{2}$ would depress the numbers of defects. To further investigate the effect of $\mathrm{Pb}(\mathrm{SCN})_{2}$ on carrier trapping process, the transient photocurrent (TPC) responses of the solar cells based on $\mathrm{MASnI}_{3}$ with different $\mathrm{Pb}(\mathrm{SCN})_{2}$ concentrations were measured. The fast turn-on/turn-off dynamics is presented in Fig. 6d. From this figure, we can find that the TPC of the device without Pb shows an overshoot, which implies that a large numbers of carriers are trapped. ${ }^{42}$ With the increasing the amount of $\mathrm{Pb}$, the overshot of the TPC response becomes weaker and disappears eventually, which means that the trapping effect of carriers is weakened by the increase of $\mathrm{Pb}$. In short, the introduction of $\mathrm{Pb}$ can reduce the defects in the Sn-based perovskites.

\section{Conclusions}

We have demonstrated that a small amount of $\mathrm{Pb}(\mathrm{SCN})_{2}$ additive in the perovskite precursors can retard the crystallization rate of the $\mathrm{MASnI}_{3}$ films during solution deposition, which 
results in a significant reduction in the pinholes and an obvious improvement in the morphology of the Sn-perovskite films. SCN ions are volatilized in the post annealing of the films, and $\mathrm{Pb}$ ions form $\mathrm{PbI}_{2}$ in the $\mathrm{MAPbSnI}_{3}$ particles. The existing of $\mathrm{PbI}_{2}$ not only passivates the Sn-perovskite particles but also benefits performance enhancement. The PSCs based on the $\mathrm{MASnI}_{3}$ film with $20 \% \mathrm{~Pb}(\mathrm{SCN})_{2}$ additive achieves a maximum PCE of $6.03 \%$, a $J_{\text {sc }}$ of $17.03 \mathrm{~mA} \mathrm{~cm}^{-2}$, an $V_{\mathrm{OC}}$ of $0.54 \mathrm{~V}$, and a $\mathrm{FF}$ of $66 \%$.

\section{Experimental}

\section{Device fabrication}

Methylammonium iodide $\left(\mathrm{CH}_{3} \mathrm{NH}_{3} \mathrm{I}\right)$, PEDOT : PSS (Clevious P VP AI 4083), $\mathrm{SnI}_{2}$ (99.999\%), PCBM (99.9\%), PEI(99.9\%), and $\mathrm{Al}$ (99.99\%) were purchased from H. C. Stark Company, Alfa Aesar, Puyang Yongxin Fullerene Technology Co., Ltd, Xi'an Polymer Light Technology Corp, sigma and China New Metal, respectively. The ITO-coated glass substrates were cleaned successively with detergent, deionized water, and isopropyl alcohol in an ultrasonic bath for $30 \mathrm{~min}$, respectively, and then treated with oxygen plasma for $15 \mathrm{~min}$. PEDOT : PSS aqueous solution was filtered through a $0.45 \mu \mathrm{m}$ filter and spin coated on the ITO surface at $3000 \mathrm{rpm}$ for $40 \mathrm{~s}$ and then annealed at $140{ }^{\circ} \mathrm{C}$ for $15 \mathrm{~min}$, forming a hole transport layer. The perovskite films without $\mathrm{Pb}(\mathrm{SCN})_{2}$ in the precursors were prepared by spin coating the precursor solutions consisting of $186.3 \mathrm{mg}$ of $\mathrm{SnI}_{2}$ and $79.5 \mathrm{mg}$ of MAI dissolved in $464 \mu \mathrm{L}$ of $\mathrm{N}, \mathrm{N}$-dimethylformamide and $36 \mu \mathrm{L}$ of dimethyl sulfoxide. The molar ratio between $\mathrm{SnI}_{2}$ and MAI is $1: 1$. The perovskite films with $5 \%$, $10 \%, 15 \%, 20 \%, 25 \%$ and $30 \% \mathrm{~Pb}(\mathrm{SCN})_{2}$ (Sigma, 99.5\%) in the precursors were prepared by spin coating the solutions with $\mathrm{Pb}(\mathrm{SCN})_{2}$. All the perovskite precursors with and without $\mathrm{Pb}(\mathrm{SCN})_{2}$ were stored at $70{ }^{\circ} \mathrm{C}$ and stirred overnight in a glove box. The following procedures for the fabrication of the solar cells were performed in a nitrogen-purged glove box. A PEDOT : PSS layer was then spin-coated onto the ITO substrates at $4000 \mathrm{rpm}$ for $60 \mathrm{~s}$ and dried at $140{ }^{\circ} \mathrm{C}$ for $20 \mathrm{~min}$. The coated substrates were then transferred to a nitrogen-filled glove-box. The perovskite layer was spin-coated on the PEDOT: PSS substrate at $5000 \mathrm{rpm}$ for $20 \mathrm{~s}$. The mixed solvent of toluene : chloroform (7:3 in volume) was used as the antisolvent during the spin-coating process. Then the perovskite film was placed in a vacuum cover and a mechanical pump was employed to keep the working pressure inside the cover at 1.325 $\mathrm{kPa}$. After 10 minutes the perovskite film was annealed at $100{ }^{\circ} \mathrm{C}$ for 10 minutes in the vacuum cover. After the fabrication of perovskite layer, PCBM was spin-cast at $2000 \mathrm{rpm}$ for $60 \mathrm{~s}$ from a $20 \mathrm{mg} \mathrm{mL} \mathrm{m}^{-1}$ chlorobenzene solution. Then PEI was spin-cast at $3000 \mathrm{rpm}$ for $60 \mathrm{~s}$ from a $0.1 \mathrm{wt} \%$ isopropanol. Finally, $\mathrm{Al}$ (90 $\mathrm{nm}$ ) was deposited through a mask via thermal evaporation at a rate of $0.2-1.0 \AA \mathrm{s}^{-1}$ to produce $0.045 \mathrm{~cm}^{2}$ pixels.

\section{Film and device characterization}

The XRD patterns were detected with a Bruker D8 Advance X-ray diffraction meter. The absorption spectra of the photoactive perovskite films coated on the ITO substrates were measured by an ultraviolet visible (UV-Vis) absorption spectrophotometer (Shimadzu UV-3101PC). The morphologies and the elemental mappings energy dispersive spectrometer (EM-EDS) of the perovskite films were investigated using a scanning electron microscope (SEM, Hitachi S-4800) with an accelerating voltage of $15 \mathrm{kV}$. The photoluminescence (PL) spectra of the perovskite films were measured by a fluorescence spectrophotometer. Fourier Transform Infrared (TRPL) spectra were performed by a square-pulsed optical excitation which was generated from a light emitting diode (LED) driven by a function generator, and a $50 \Omega$ input termination of the oscilloscope was used. The current density-voltage $(J-V)$ curves of the inverted PSCs were measured by a Keithley 6430 Source Measure Unit under nitrogen and a Mass $1.5 \mathrm{G}$ illumination at $100 \mathrm{~mW} \mathrm{~cm}^{-1-2}$ (SAN-EI Electric, XEC-301S). The incident photon-to-current efficiency (IPCE) was performed using a solar cell QE/IPCE measurement system (Zolix Solar Cell Scan 100). The light intensity dependent photo voltage (LIPV) was conducted using an array of 12 focused cool white LEDs of $1 \mathrm{~W}$. The stability test was carried out in air with $50 \%$ humidity. The light intensity of the LEDs was detected by a corrected Si photodiode, and the electrical input power of the LEDs was adjusted with a controlled power supply to change the illumination intensities ranging from 5 to $500 \mathrm{~mW} \mathrm{~cm}{ }^{-2}$. The values of the open-circuit voltage $\left(V_{\mathrm{oc}}\right)$ and the short-circuit current density $\left(J_{\mathrm{sc}}\right)$ were collected by a 16 bit data acquisition board (NI-6052E) with an input impedance of $10 \mathrm{M} \Omega$ and $50 \Omega$ at room temperature, respectively. In order to reach a steady-state condition, the time of the data acquisition was chosen to be $100 \mathrm{~ms}$ through the measurement process. The transient photocurrent (TPC) measurement was conducted using a signal generator with a voltage signal of $200 \mu \mathrm{s}$ and $50 \mathrm{~Hz}$ as a power supply of the white LEDs that produced pulsed light. The device was connected with a resistor of $50 \Omega$ in series and the voltage applied to the resistor was collected by the oscilloscope and the TPC was calculated simply by the voltage divided by the resistance.

\section{Conflicts of interest}

There are no conflicts to declare.

\section{Acknowledgements}

This work was supported by the Natural Science Foundation of China (Grant No. 61475017)

\section{Notes and references}

1 A. Kojima, K. Teshima, Y. Shirai, et al., J. Am. Chem. Soc., 2009, 131(17), 6050-6051.

2 H. S. Kim, C. R. Lee, J. H. Im, et al., Sci. Rep., 2012, 2, 591.

3 N. G. Park, J. Phys. Chem. Lett., 2013, 4(15), 2423-2429.

4 W. S. Yang, J. H. Noh, N. J. Jeon, et al., Science, 2015, 348(6240), 1234-1237.

5 M. M. Lee, J. Teuscher, T. Miyasaka, et al., Science, 2012, 338(6107), 643-647. 
6 M. Liu, M. B. Johnston and H. J. Snaith, Nature, 2013, 501, 395.

7 H. Zhou, Q. Chen, G. Li, et al., Science, 2014, 345(6196), 542546.

8 D. Bi, W. Tress, M. I. Dar, et al., Sci. Adv., 2016, 2(1), e1501170.

9 W. Chen, Y. Wu, Y. Yue, et al., Science, 2015, 350(6263), 944948.

10 D. P. McMeekin, G. Sadoughi, W. Rehman, et al., Science, 2016, 351(6269), 151-155.

11 Q. Wang, Q. Dong, T. Li, et al., Adv. Mater., 2016, 28(31), 6734-6739.

12 C. C. Stoumpos and M. G. Kanatzidis, Halide Perovskites:, Adv. Mater., 2016, 28(28), 5778-5793.

13 D. Bi, P. Gao, R. Scopelliti, et al., Adv. Mater., 2016, 28(15), 2910-2915.

14 NREL, Best Research-Cell Efficiencies, https://www.nrel. Gov/pv/assets/images/efficiency-chart.png, (accessed: April 2017).

15 N. K. Noel, S. D. Stranks, A. Abate, et al., Energy Environ. Sci., 2014, 7(9), 3061-3068.

16 F. Hao, C. C. Stoumpos, R. P. H. Chang, et al., J. Am. Chem. Soc., 2014, 136(22), 8094-8099.

17 (a) S. Rühle, Sol. Energy, 2016, 130, 139-147; (b) Z. Yang, A. Rajagopal, C. C. Chueh, S. B. Jo, B. Liu, T. Zhao and A. K. Jen, Adv. Mater., 2016, 28, 8990.

18 M. H. Kumar, et al., Adv. Mater., 2014, 26(41), 7122-7127.

19 F. Hao, et al., J. Am. Chem. Soc., 2015, 137(35), 11445-11452.

20 F. Hao, et al., Nat. Photonics, 2014, 8(6), 489-494.

21 F. Zuo, S. T. Williams, P. W. Liang, et al., Adv. Mater., 2014, 26(37), 6454-6460.

22 W. Liao, D. Zhao, Y. Yu, N. Shrestha, K. Ghimire, C. R. Grice, C. Wang, Y. Xiao, A. J. Cimaroli, R. J. Ellingson, N. J. Podraza, K. Zhu, R.-G. Xiong and Y. Yan, J. Am. Chem. Soc., 2016, 138, 12360.
23 T. Yokoyama, et al., J. Phys. Chem. Lett., 2016, 7(5), 776-782. 24 C. Roldan-Carmona, P. Gratia, I. Zimmermann, et al., Energy Environ. Sci., 2015, 8(12), 3550-3556.

25 H. Dong, Z. Wu, J. Xi, X. Xu, L. Zuo, T. Lei and A. K. Y. Jen, Adv. Funct. Mater., 2018, 28(2), 1870013.

26 X. Li, F. Hao, X. Zhao, et al., ACS Appl. Mater. Interfaces, 2017, 9(40), 34833-34843.

27 Y. Takahashi, et al., Dalton Trans., 2011, 40(20), 5563-5568.

28 D. Zhao, et al., Nat. Energy, 2017, 2, 17018.

29 F. Hao, et al., J. Am. Chem. Soc., 2014, 136(20), 8094-8099.

30 Y. Li, et al., Adv. Energy Mater., 2016, 6(20).

31 Y. Ogomi, et al., J. Phys. Chem. Lett., 2014, 5(20), 1004-1011.

32 L. Zhu, et al., Nanoscale, 2016, 8(20), 7621-7630.

33 F. Zuo, et al., Adv. Mater., 2014, 26(20), 6454-6460.

34 D. Bi, W. Tress, M. I. Dar, P. Gao, J. Luo, C. Renevier, K. Schenk, A. Abate, F. Giordano, J.-P. C. Baena, J.-D. Decoppet, M. Gratzel, A. Hagfeldt, et al., Sci. Adv., 2016, 2, e1501170.

35 M. Zhang, M. Lyu, J.-H. Yun, M. Noori, X. Zhou, N. A. Cooling, Q. Wang, H. Yu, P. C. Dastoor and L. Wang, Nano Res., 2016, 9, 1570-1577.

36 B. Zhao, M. Abdi-Jalebi, M. Tabachnyk, et al., Adv. Mater., 2017, 29(2), 1604744.

37 X. Huang, L. Lv, Y. Hu, et al., Org. Electron., 2017, 42, 107114.

38 L. J. A. Koster, V. D. Mihailetchi, R. Ramaker, et al., Appl. Phys. Lett., 2005, 86(12), 123509.

39 D. Zhao, M. Sexton, H. Y. Park, et al., Adv. Energy Mater., 2015, 5(6), 1401855.

40 J. C. Blancon, W. Nie, A. J. Neukirch, et al., Adv. Funct. Mater., 2016, 26(24), 4283-4292.

41 N. Marinova, W. Tress, R. Humphry-Baker, et al., ACS Nano, 2015, 9(4), 4200-4209.

42 L. Longfeng, et al., Chem. Mater., 2014, 27(1), 44-52. 